\title{
Webduc: Uma proposta de ferramenta de avaliação formativa no ambiente TelEduc
}

\author{
André Bastos * \\ Rita Cristina Galarraga Berardi ** \\ Ricardo Azambuja Silveira***
}

Resumo. Este artigo descreve as características e funcionalidades de uma ferramenta para avaliação formativa integrada ao ambiente de ensino a distância TelEduc, a qual foi desenvolvida com o objetivo de auxiliar os formadores no processo de geração automática de exercícios e na aplicação dos mesmos aos alunos inscritos nos cursos, como uma forma de propiciar a estes uma auto-avaliação de seu rendimento e aprendizado. Sendo utilizado para a implementação dessa ferramenta a linguagem PHP associada ao gerenciador de banco de dados MySQL e tendo-se realizado um estudo sobre os métodos de avaliação mais adequados ao ambiente em questão.

Palavras-chave: Educação a distância, avaliação formativa, TelEduc

\begin{abstract}
This paper describes the principles, the features and the architecture of a formative assessment tool designed to be used in the Teleduc distance learning environment. The assessment tool was developed as an auxiliary evaluation instrument for teacher in order to activate a automatic generation process of exercises and the application of these exercises to the students. These exercises can be used as a self assessment tool by the students of the Teleduc courses. The system was developed in PHP programming language and uses the MYSQL database management system according to an accurate study about assessment methodology.
\end{abstract}

Key words: Distance Education, Evaluation, TelEduc

\footnotetext{
* Bolsista de DTI (UFRGS); adbastos @ inf.ufrgs.br;

** Graduando em Ciência da Computação (UFPEL); ritacgbl@ufpel.edu.br;

*** Doutor em Ciência da Computação (UFPEL); rsilv@ufpel.edu.br
}

\section{Introdução}

Os projetos de ensino a distância mediado por computador e pela Internet, cada vez mais, tem ganhado a atenção da comunidade acadêmica e se tornado cada vez mais presente no nosso dia-a-dia. Fato este confirmado pelo crescente número de instituições oferecendo cursos a distância pelo mundo, beneficiando inúmeras atividades na sociedade, como pesquisa, educação e treinamento [Sant 2002].

Atualmente, no Brasil, um desses ambientes de ensino é o TelEduc [Tele 2003], o qual é um software livre, com código aberto, cuja versão mais recente (3.0) foi concebida utilizando a linguagem PHP (PHP Hypertext Processor) associada ao gerenciador de banco de dados MySQL, proporcionando, com isso, a implantação de 
funcionalidades adicionais e uma segmentação de dados por cursos, fazendo com que o tempo de acesso aos mesmos passasse a ser influenciado apenas pelo volume de interação entre seus usuários e não pelo número de cursos na base, como ocorria nas versões anteriores do sistema em Lite e MiniSQL [Tele 2003].

Outra mudança obtida com essas novas tecnologias foi a de tornar mais flexível a escolha dos ambientes, podendo ser instalado em vários sistemas operacionais. Até então, era exigida a utilização apenas em ambiente Linux e seguro.

Devido à forma participativa com a qual o Teleduc foi desenvolvido, com todas as suas ferramentas idealizadas, projetadas e depuradas segundo necessidades relatadas por seus usuários, motivou-se o interesse em agregar ao mesmo novas funcionalidades. A partir do seu uso freqüente por um público diversificado, estes novos recursos têm se feito necessários, principalmente em relação ao acompanhamento mais efetivo do aprendizado e avaliação dos alunos envolvidos em um curso [Roch 2002].

Em vários ambientes de educação a distância $(\mathrm{EaD})$ disponíveis no mercado, tais como Aulanet [Aula 2003], WebCT [Webc 2003] e LearningSpace [Lear 2003], existem ferramentas de avaliação que, em geral, permitem ao professor escolher níveis de dificuldades e os tipos de questões em cada teste, sendo elas posteriormente corrigidas automaticamente pelo sistema ou pelo próprio formador, de modo a fornecer aos alunos a verificação de suas respostas corretas e erradas.

Deve considerar também, o fato de que existe, atualmente, uma busca por mudanças no paradigma de avaliação, passando de um modelo baseado em testes pontuais para uma avaliação formativa, tanto em cursos presenciais quanto a distância. Na modalidade a distância, esta forma de avaliação tem relevância ainda maior, possibilitando o acompanhamento do comportamento do aprendiz [Otsu 2002].

No caso do TelEduc, houve a constatação de que não existia até então nenhum mecanismo semelhante ao adotado em outros ambientes de $\mathrm{EaD}$ e que estivesse integrado ao mesmo para complementação do processo de avaliação, através de uma ferramenta mais efetiva e que fornecesse um realimentação aos professores e alunos, mesmo sem o papel desempenhado pelas interações face a face.

Com base nas suas características e no quadro exposto, despertou-se então o interesse na ampliação do TelEduc, agregando-lhe facilidades que possibilitassem aos formadores elaborarem avaliações formativas e aplicá-las aos alunos, propiciando assim a verificação do rendimento destes.

Este artigo apresenta a criação de uma ferramenta para o preenchimento dessa lacuna existente no ambiente, a qual é responsável pela geração automática de exercícios, a partir de questões cadastradas previamente pelos formadores e dos tipos disponíveis nessa versão dela (dissertativas, múltipla-escolha, relacionar colunas e verdadeiro/falso).

O objetivo buscado com sua implantação foi fornecer uma alternativa para a geração de conjuntos de exercícios que se somam às diversas ferramentas oferecidas no TelEduc e que podem ser utilizados pelos aprendizes para obter um melhor acompanhamento do seu rendimento, com base no resultado das avaliações e em observações inseridas pelo formador.

Do ponto de vista prático, adotou-se para desenvolvimento da Webduc as mesmas tecnologias empregadas na versão 3.0 do TelEduc, ou seja, o PHP e MySQL, de forma a promover uma completa integração com o ambiente e as ferramentas já existentes (figura 1) e também por serem softwares livres. 


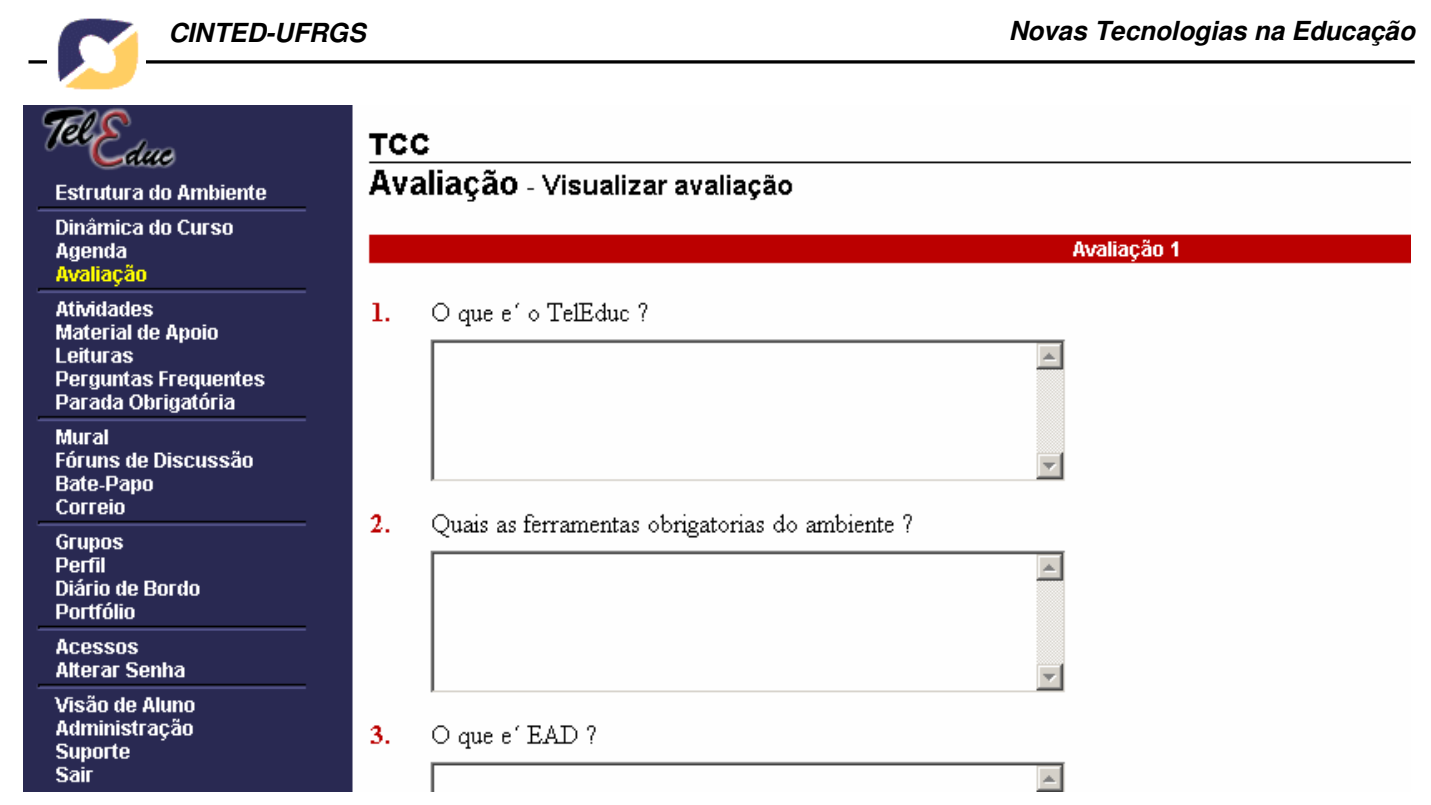

Figura 1. Ferramenta de Avaliação Formativa

\section{Avaliação Formativa}

Avaliação é a coleta sistemática de evidências por meio das quais determinam-se mudanças que ocorrem nos alunos e como elas ocorreram [Bloo 1973].

Sendo que, é formativa toda a avaliação que ajuda o aluno a aprender e a se desenvolver, que participa da regulamentação das aprendizagens e do desenvolvimento no sentido de um projeto educativo [Perr 1999].

Segundo Carla Wandscheer Krieger Langsch [Lang 1999], existem várias técnicas para realização da avaliação, mas é importante definir qual seu objetivo, ou seja, se é apenas uma mera medida ou uma referência para contribuir em futuras aprendizagens. Pois, através da análise de resultados podem ser traçados novas estratégias e caminhos de ensino-aprendizagem.

Com isso, pode-se dividir a avaliação sob dois enfoques: o tradicional, no qual se busca verificar se os objetivos educacionais foram atingidos e se houve a aprendizagem do aluno, preocupando-se basicamente com a parte cognitiva; e o enfoque da avaliação integral, que leva em consideração todas as dimensões do comportamento humano de forma interrelacionada, para buscar um maior desenvolvimento do indivíduo [Lang 1999].

Como exemplo de classificação das formas de avaliação pode-se ter: a técnica baseada nas observações registradas durante o processo de ensino-aprendizagem (desenvolvimento intelectual, persistência no desenvolvimento de tarefas, facilidade de assimilação do conteúdo, etc), com o objetivo de poder redirecionar-se o trabalho; a auto-avaliação e a técnica baseada em testes padronizados (devem ser preparados por um especialista no assunto, sendo aplicados a um grande número de pessoas e podendo ser repetido inúmeras vezes) e testes escolares (preparados e analisados pelo próprio professor, sendo utilizados uma única vez para avaliar os objetivos do momento e destinam-se a um determinado grupo. Por exemplo, testes orais, práticos, objetivos e dissertativos).

É altamente desejável que um ambiente de EaD tenha uma ferramenta capaz de propiciar meios pelos quais os alunos que participam dos cursos ou aulas possam se avaliar e que o professor possa acompanhar este processo e auxiliar os alunos, já que a avaliação está diretamente relacionada com o ou o processo de ensino-aprendizagem. E este é parte de um ciclo fundamental na construção do conhecimento dos alunos, pois a 
avaliação faz parte deste ciclo como um elemento sistemático de correção de rumo, de auxilio para que o professor possa corrigir e melhorar o seu processo de ensino e de auxilio ao aluno para que ele possa perceber e rever onde estão suas deficiências. Caso o professor perceba dificuldades gerais no aprendizado dos alunos ele deve auxiliar o aluno para que possam, juntos, rever para melhorar e aperfeiçoar o processo de ensinoaprendizagem [Hack 2000] [Immi 2002].

Cabe salientar que no Brasil a avaliação da aprendizagem em ambientes de $\mathrm{EaD}$ é regulamentada por lei e deve incluir testes presenciais, podendo serem realizadas ainda outras formas de avaliação em conjunto com esta, sendo de responsabilidade da Instituição credenciada para ministrar esse tipo de curso [Mini 2003].

Nesse contexto, o TelEduc possui ferramentas projetadas para facilitar tanto o desenvolvimento de atividades baseadas na construção de conhecimento pelo aprendiz como de aprendizagem colaborativa (que enfocam a participação dos alunos através de ferramentas como Chat, fóruns de discussão, correio, etc) [Otsu 2002]. Dessa forma, com a inclusão da Webduc pretende-se contribuir no processo de avaliação formativa do ambiente, ressaltando que esta é realizada em conjunto com as demais ferramentas existentes na estrutura atual do ambiente.

\section{Webduc}

Baseando-se na análise do processo de avaliação em alguns ambientes de EAD, tais como o WebCT, LearningSpace e Aulanet, optou-se pela implementação na etapa inicial de desenvolvimento da ferramenta por questões dissertativas, de múltiplaescolha, de relacionar colunas e questões tipo verdadeiro ou falso, deixando-se para trabalhos futuros a inclusão de novos tipos de exercícios e funcionalidades, levando em conta possíveis sugestões dos usuários e a análise dos resultados a serem alcançados com a utilização da mesma nos vários cursos do TelEduc.

Assim como as demais ferramentas integradas ao TelEduc, a de avaliação possui dois ambientes distintos: do formador (ver secção 3.2) e do aluno (ver secção 3.3), cada qual possuindo opções próprias, de acordo com o status do usuário.

O acesso ao ambiente de formador ou aluno implica na realização de verificação de autenticação e acesso ao curso pelo usuário. De acordo com essas informações, este obtém a permissão para visualizar e utilizar as opções de determinado ambiente.

\subsection{Ambiente do formador}

Este ambiente (figura 2) é composto pelas seguintes opções de gerenciamento da ferramenta:

TCC

Avaliação

Usuário: André Dias Bastos

Cadastrar questies

Visualizar cadastradas

Questies nor walliacăo

Visualizar amaliacăo

Cadastrar yalarito

Veriicar respostas

Figura 2. Ferramenta de Avaliação (visão do formador)

a) cadastrar questões - permite o acesso do formador ao cadastro dos quatro tipos de questões propostos, podendo ser cadastrada uma quantidade não estipulada de exercícios, de cada um dos tipos, no banco de dados. 
b) visualizar cadastradas - possibilita a visualização de todas as questões do tipo de questão selecionado. Também através dessa opção é possível excluir questões cadastradas.

c) questões por avaliação - opção utilizada para que os formadores selecionem a quantidade de questões de cada tipo (entre 0 e 10) que será aplicada e o número da avaliação correspondente (entre 1 e 9), conforme é mostrado na figura 3.

Os valores armazenados podem ser atualizados ou modificados pelo formador enquanto a respectiva avaliação não tiver sido respondida por nenhum aluno. Outra restrição existente é que a quantidade de questões não pode ser zero para todos os tipos de questão disponíveis.

\section{TCC \\ Avaliação - Quantidade de questões por avaliação}

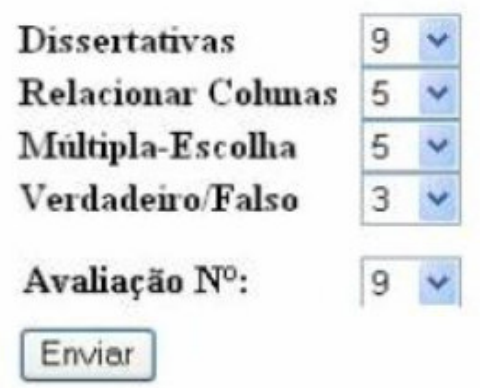

Figura 3. Quantidade de questões por avaliação

d) visualizar avaliação - utilizado para que os formadores possam enxergar como será vista cada avaliação pelo aluno.

As questões são aplicadas em cada teste de acordo com a quantidade por avaliação selecionada pelo formador. Por exemplo, se foi estabelecido que a avaliação 1 terá cinco questões de um tipo, a avaliação seguinte conterá a quantidade determinada para esse segundo teste, sendo mostradas a partir da sexta questão do tipo e assim por adiante para as demais avaliações, ou seja, sendo feito a contagem das questões aplicadas nas avaliações anteriores e mostrando a partir desse número no cadastro.

e) cadastrar gabarito - opção responsável pelo cadastro do gabarito das questões de múltipla-escolha, relacionar colunas e verdadeiro/falso, possibilitando dessa maneira a correção automática desses exercícios em cada avaliação.

f) verificar respostas - permite a verificação das respostas dos exercícios de cada avaliação, enviadas pelos alunos. Após selecionar o número da avaliação e o tipo de questão, o formador tem acesso à lista de alunos inscritos no curso, podendo assim consultar suas respectivas respostas em determinado teste.

Caso o gabarito das questões dos tipos múltipla-escolha, relacionar colunas e assinalar verdadeiro/falso já tenham sido cadastrados, o formador visualizará as respectivas questões corrigidas (figura 4), economizando dessa forma o tempo que seria necessário para corrigi-las em cada teste do aluno individualmente. Além disso, propicia que os alunos tenham acesso à pelo menos parte da correção, restando apenas as questões dissertativas (se houverem no teste, conforme escolha realizada na opção "questões por avaliação"). Do contrário, será exibida uma mensagem de que o formador ainda não cadastrou o gabarito daquela avaliação. 
TCC

Avaliação - Verificar respostas

Usuário: Michelle Cardoso

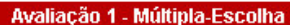

1) Qual dessas ferramentas tem uso obrigatorio no TelEduc ?

A $\mathbf{A}$

a) atividades

b) dinamica do curso

c) acessos

d) correio

e) perfil

2) Qual dessas ferramentas e' de uso exclusivo dos formadores

a) administraçao

b) agenda

c) atividades

d) correio

e) material de apoio

Figura 4. Verificar respostas múltipla-escolha

Para as questões dissertativas é mostrado, na tela, a pergunta, a resposta do aluno e um campo para que o formador comente esta (figura 5). Se ele já tiver corrigido esse teste, será mostrado o comentário inserido anteriormente, ao invés do formulário.

TCC

Avaliação - Verificar respostas

Usuário: Michelle Cardoso

1. Questão: $O$ que e' o TelEduc ?

Resposta: Ambiente de EaD.

Incluir comentário:

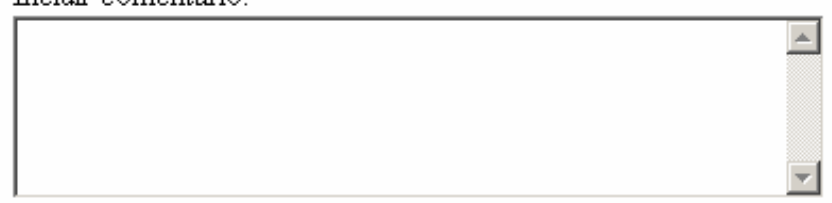

Figura 5. Verificar respostas dissertativas

\subsection{Ambiente do aluno}

Como mostrado na figura 6 , aos alunos é possível visualizar as opções descritas a seguir: 
TCC

Avaliação

Usuário: Michelle Cardoso

Avaliacäo

Conreçä

Figura 6. Ferramenta de Avaliação (visão do aluno)

a) avaliação - fornece aos alunos acesso às avaliações disponibilizadas pelo formador para aplicação. Cada teste é apresentado ao aluno com as questões de todos os tipos sendo mostradas na mesma página. O número de questões de cada tipo, como foi visto anteriormente, depende das quantidades por avaliação estabelecida pelo formador.

Quando os alunos respondem uma avaliação, suas respectivas respostas, identificação de usuário e o número de questões aplicados no teste são salvos em tabelas diferentes no banco de dados, uma para cada tipo de questão presente no teste.

b) correção - propicia um feedback ao aluno, permitindo que consulte suas respostas em determinada avaliação que respondeu, verificando quais questões acertou ou não e tendo acesso ao gabarito, para que ele possa aprender com seus erros.

A correção é mostrada em cada avaliação pelo tipo de questão selecionada. Isso se dá pelo fato das questões dissertativas não terem seus gabaritos cadastrados, pelos quais pudessem ser comparadas com as respostas do aluno automaticamente. Cada resposta desse tipo deve ser analisada individualmente pelo formador, disponibilizando a correção posteriormente.

\subsection{Arquitetura}

A arquitetura implementada no modelo proposto é mostrada graficamente na figura 7.

O acesso para o usuário ocorre através de requisições ao servidor Apache, que interage com algum código PHP da ferramenta, o qual por sua vez realiza o acesso aos dados armazenados no banco de dados MySQL, retornando ao cliente as informações.

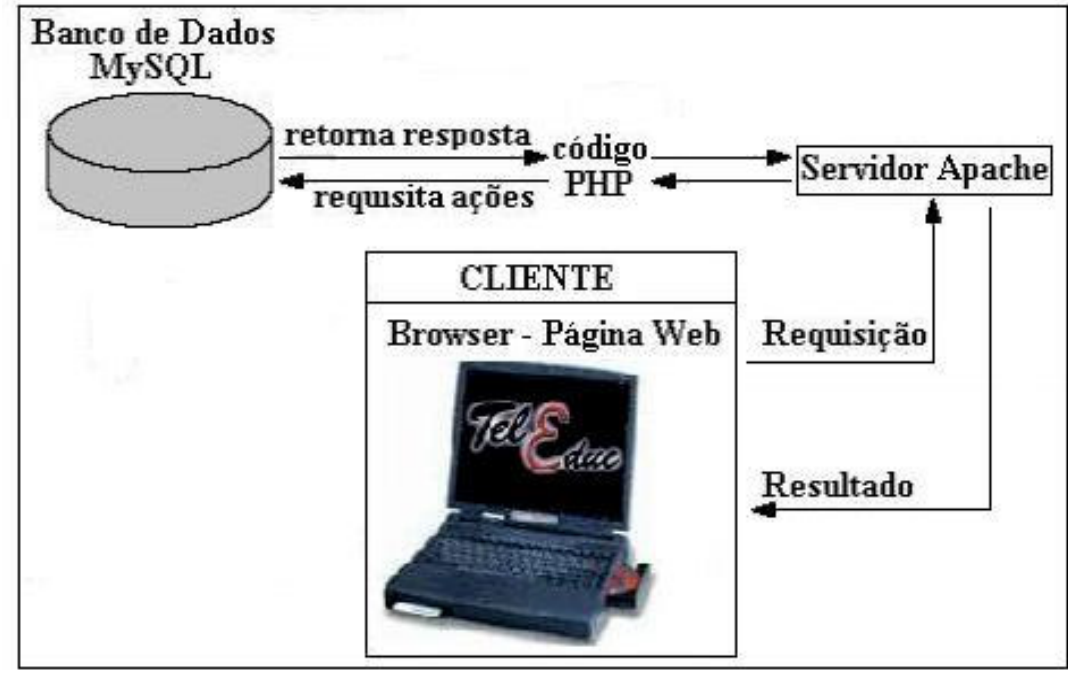

Figura 7. Arquitetura da Webduc 


\subsection{Agregação ao Ambiente}

Estuda-se o desenvolvimento de um mecanismo de instalação mais imediata da ferramenta. A priori sua instalação era feita manualmente, o que prejudicava bastante a praticidade de agregação .Portanto observou-se a necessidade de um script de instalação,cuja implementação está em fase final de desenvolvimento.

O script adapta WebDuc à versão 3.1.8 do TelEduc, para isso fez-se necessário a modificação em alguns aspectos com relação ao Banco de Dados, visto que o software para avaliação foi criado baseado na versão 3.0.2 do ambiente TelEduc.

\section{Conclusões}

A metodologia de EAD com auxílio da Internet é uma das tendências mais fortes dos últimos tempos, apresentando inúmeros benefícios para o processo educacional, tais como possibilitar a chance de aprendizado a pessoas que tem dificuldades ou não podem se deslocar até uma instituição de ensino tradicional.

Nesse contexto, o TelEduc por apresentar uma grande facilidade de uso e ser um software livre, construído de acordo com as necessidades pedagógicas dos seus usuários, constituí-se num ambiente com ainda grandes perspectivas de crescimento.

Com o desenvolvimento da ferramenta de avaliação, mostrada neste artigo, alcançou-se o objetivo de disponibilizar um recurso necessário, mas que até então não havia sido implementado no TelEduc, propiciando um mecanismo para auxiliar na verificação do rendimento dos alunos, inscritos nos cursos e permitindo aos formadores economizarem tempo na criação dos exercícios e em correções e, principalmente, auxiliando o processo de avaliação formativa através do ambiente.

Como trabalhos futuros, deseja-se acrescentar novas funcionalidades à ferramenta, tais como outros tipos de questões, estatística de acertos e níveis de dificuldade dos exercícios, baseando-se para isso nos resultados obtidos da sua implantação em diferentes cursos e em sugestões dos seus usuários.

\section{Referências}

AulaNet. (2003) - AulaNet 2.0 - 1997-2003. Fundação Padre Leonel França - PUC Rio de Janeiro. Disponível por www em: http://asgard.les.inf.puc-rio.br/aulanet/ (10, abril 2003)

Bloom, B. S.; et al. "Taxonomia de objetos educacionais, Domínio cognitivo". Porto Alegre: Globo, 1973.

Hack, Luciano Emilio. (2000) "Mecanismos Complementares para a avaliação do aluno na Educação a Distância". Porto Alegre: Programa de Pós-Graduação em Computação da UFRGS. Dissertação de Mestrado.

Immig, H. (2002) "Avaliação da aprendizagem em ambientes de Educação a Distância". Novo Hamburgo: FEEVALE.

Langsch, Carla Wandscheer Krieger. (1999) “Avaliação no Ensino à Distância via Web”. Porto Alegre: Programa de Pós-Graduação em Computação da UFRGS.

LearningSpace (2003) - Lótus LearningSpace 5.0. Disponível por www em http://www.lotus.com/products/learnspace.nsf/wdocs/homepage (07, abril 2003) 
Ministério da Educação. (2003) - Legislação educacional. Disponível por www em: http://www.mec.gov.br/legis/default.shtm (7, junho 2003)

Otsuka, J. L.; Lachi, R. L.; Ferreira, T. B.; Rocha, H. V. (2002) "Suporte à Avaliação Formativa no Ambiente de Educação a Distância TelEduc". In: Anais do VI Congresso Iberoamericano de Informática Educativa (IE2002), Vigo, España 20-22 noviembro.

Perrenoud, P. (1999) "Avaliação: da excelência à regulamentação das aprendizagens entre duas lógicas". Porto Alegre: Artes Médicas.

Rocha, H. V. (2002) "O ambiente TelEduc para Educação à Distância baseada na Web: Princípios, Funcionalidades e Perspectivas de desenvolvimento". In: Moraes, M. C. (Org). Educação à Distância: Fundamentos e Práticas. Campinas, SP: Unicamp/Nied, pp. 197-212.

Santos, Rodrigo Gomes dos. (2002) "JtelEduc Chat: um novo Ambiente de Diálogo Interativo para o sistema TelEduc, modelado em UML e construído em PHP/MySQL e Java". Canoas: ULBRA. Trabalho de Conclusão.

TelEduc (2003) - TelEduc Ambiente de Ensino a Distância. Disponível por www em http://teleduc.nied.unicamp.br/teleduc (03, junho 2003)

WebCT (2003) - WebCT. Disponível por www em http://www.webct.com/ (07, abril 2003) 